\title{
Horizontes de lo común: sujetos y comunidades post-identitarios
}

\author{
Horizons of the commons: Post-identitarian Subjects \\ and Communities
}

\section{Manuel Cruz y Alicia García Ruiz}

Universidad de Barcelona

1. "Horizontes de lo común" tiene como objetivo ofrecer una cartografía del debate filosófico contemporáneo en torno a la noción de lo "común" y a la figura política de la comunidad. Desde que, sobre las ruinas del comunismo estalinista, Bataille formuló su famosa "exigencia de comunidad", la pregunta por lo común se ha ido cargando de una potencia crítica insoslayable para la filosofía actual. A la altura ya del siglo XXI nos hallamos inmersos en una profunda perplejidad. Por un lado, el gigantismo institucional y sus inercias parecen asfixiar la capacidad política de actuar conjuntamente y, de modo más concreto, de innovar la vida pública con criterios y cursos de acción verdaderamente plurales, que vayan más allá del simulacro organizado de pluralidad que es la esfera del consumo. Pero, por otro lado, experimentamos también una dispersión de referentes y lenguajes comunes, imprescindibles para la politización. Una atomización que la actual crisis económica y social no ha hecho más que poner de manifiesto, puesto que la cultura individualista forjada durante décadas fue su sustrato.

2. Nos hallamos, pues, en un impasse del tiempo histórico. Se trata de una fisura en la que todo un legado de experiencias políticas se encuentra en cuestión. Por un lado, contemplamos la imposibilidad de una propuesta nostálgica de comunidad política orgánica, cuyos intentos de realización histórica a menudo han degenerado en formas totalitarias. Pero también nos enfrentamos con la dificultad para reconstruir una interpretación política operativa sobre lo que significa la vida en común, capaz de sortear esta traumática experiencia histórica. Ante la tentación de caer en nuevos fundamentalismos identitarios o frente al problema de cómo estabilizar las demandas de los movimientos sociales que claman por una forma distinta de organizar la política o bien, finalmente, ante el desafío de cómo rehacer de un modo pluralista las premisas normativas de sociedades cada vez más complejas, nos asaltan preguntas ineludibles, que reverberan a lo largo de los textos 
recogidos en la parte monográfica del presente número de Isegoría ¿En nombre de quién habla la voz de una comunidad? ¿Implica la pertenencia a una comunidad el consentimiento para que, en nuestro nombre, cada norma sea considerada una traslación al plano colectivo de nuestra voluntad? ¿Es lo mismo la comunidad política que el hecho de vivir en común? ¿Cuál es la naturaleza ontológica del espacio político que nos une o nos separa (o tal vez ambas cosas)?

3. Tenemos, sin duda, ante nosotros, como Hannah Arendt hubiera formulado, "una herencia sin testamento". A medida que penetramos en el siglo XXI, el vocabulario heredado de la teoría política moderna experimenta una presión creciente sobre algunas de sus categorías centrales. Las profundas transformaciones sociales, económicas y tecnológicas operadas durante el siglo XX y, de modo más concreto, el surgimiento de formas de organización colectiva no necesariamente de carácter o escala estatal se sitúan entre los factores responsables de esta presión. A la luz de los procesos de crisis institucional e involución del vínculo social en las democracias liberales contemporáneas, se están activando nuevos focos de experiencia colectiva e innovación político-semántica que apuntan hacia algo que cabe calificar como un desbordamiento del discurso político-filosófico y, más específicamente, de sus formas y figuras de argumentación.

Semejante desbordamiento comporta, por lo menos, dos tipos de consecuencias. En primer lugar, desde dentro de la práctica académica, la toma de consciencia de aquello que en otros tiempos, por contraposición al riesgo de autorreferencialidad y clausura del pensamiento, se llamó la praxis o la intervención crítica sobre lo real. En segundo lugar y, en relación con el programa filosófico que autores como Foucault concibieron como ontología del presente, emerge la necesidad de pensar desde lugares teóricos distintos las relaciones entre lógicas de los sujetos y lógicas de la vida. En esta dirección crítica, un concepto tan central para la teoría política como el de soberanía ha de resultar particularmente sometido a revisión.

4. Atravesamos, por tanto, un momento de profunda crítica conceptual del discurso político moderno, que ha sido largamente asociado a la forma Estado-nación y a sus instituciones, entendidos como único escenario pensable de la vida política, así como a una determinada noción de validez normativa. En este sentido, términos como justicia, igualdad, universalidad, racionalidad, validez, normatividad o comunidad son sometidos en la actualidad a un exigente escrutinio, cuando no a una verdadera deconstrucción. A este respecto, no hay un criterio unánime en cuanto a la estrategia por seguir. Algunas posiciones teóricas convocan al abandono definitivo de la mayoría de estas categorías políticas, especialmente de las vinculadas de manera más directa a los ideales de la Ilustración, como las de ra- 
cionalidad y normatividad. Para ellas, la progresiva crisis de legitimidad que se manifiesta hoy en las instituciones políticas modernas se acompaña del vaciamiento de sentido de tales categorías políticas tradicionales. Otras posiciones, en cambio, señalan la necesidad de perfeccionar, sin por ello abandonarlas, esas mismas categorías, dotándolas de nuevos contenidos a la altura del presente histórico y de sus desafíos, tanto conceptuales como prácticos.

En todo caso, la controversia actual sobre la crisis de representación, puesta de manifiesto en la insuficiencia de estos términos de la política que nos legó la Modernidad para dar cuenta de muchas de las nuevas escalas, agentes y dinámicas políticas, es una cuestión central para la filosofía contemporánea en general y no sólo política. En nuestro volumen se pretende afrontar estas interrogantes ofreciendo diversas exploraciones en la línea del análisis ontológico de los fundamentos políticos de la modernidad. Más específicamente, esta crítica ontológica de la modernidad se concentra sobre las consecuencias y limitaciones de la idea moderna de sujeto político y moral para dar cuenta de los desafíos contemporáneos en el campo de la conceptualización del vínculo social.

5. La discusión de tal idea de sujeto tutela y focaliza uno de los puntos ineludibles en cualquier reconstrucción de la andadura del concepto de comunidad política en el panorama filosófico del siglo XX, a saber, el debate entre liberales y comunitaristas. Como es sobradamente conocido, el liberalismo de orientación neokantiana generó la reacción comunitaria romántica y su idea de sujetos historizados y pertenecientes a comunidades orgánicas, cuyo testigo fue recogido por los actuales comunitaristas neohegelianos y neoaristotélicos. La consecuencia es la siguiente: además de las notables y conocidas diferencias, liberales y comunitaristas comparten un poderoso presupuesto, un presupuesto identitario por más señas. Los dos parecen necesitar alguna variante de la idea de identidad, sea la singular -liberal- sea la orgánica -comunitarista-.

6. Frente a tal orientación, como ya se ha adelantado en cierto modo, las nuevas filosofías de la comunidad apuntan hacia un análisis ontológico de los fundamentos políticos de la modernidad, que pasa por una potente exploración del estatuto ontológico de lo común. Para ello, ponen en marcha una compleja crítica del enfoque identitario, en el plano de lo colectivo, y de las formas de subjetividad moderna, en el plano de lo individual. El resultado es una verdadera "conversación" filosófica intertextual que dará lugar al característico entramado conceptual que es posible reconocer en todas ellas, por encima de las variantes particulares. En este entramado se va haciendo patente el intento compartido de articular una nueva forma de pensar lo común, que sea capaz de escapar de una doble jaula conceptual. Por el lado político, en resonancia con las aportaciones de autores como Fou- 
cault, Derrida o Bataille, se pretende huir del paradigma hobbesiano de la soberanía y sus formas derivadas de subjetivación política y moral. Por el lado ontológico, a su vez, se intenta deshacer la antinomia entre singular y plural, como pretenden elaborar conceptualmente autores como Roberto Esposito, Jean Luc Nancy, Jacques Rancière o Giorgio Agamben.

En relación con el mencionado debate entre liberales y comunitaristas, estas filosofias de la comunidad, de inspiración postheideggeriana en su mayor parte, suponen la voluntad de salir de la órbita de una controversia que amenazaba por convertirse en circular. Frente a ello, las propuestas filosóficas citadas han planteado de manera decidida la cuestión de los límites de la enunciación de las categorías políticas modernas y románticas puestas en juego por los liberales y comunitaristas, discutiendo el carácter referencial y estatuto metafísico de las mencionadas categorías. Y para ello han señalado o hecho uso de dimensiones y lenguajes que tradicionalmente no habían sido atendidos en el análisis político, tales como la inserción de la vida biológica como dimensión política primaria o los cauces expresivos de latencias políticas presentes en la literatura y el arte.

7. Lejos de constituir mero eco o variante de moda teórica alguna, las interrogaciones que emergen en la controversia contemporánea sobre la figura de la comunidad y el estatuto teórico de lo común son de un calado y alcance que tan sólo hemos comenzado a atisbar. Como suele suceder, la realidad camina unos cuantos pasos más adelante que nuestra mirada teórica y la crisis institucional, política y social que atravesamos nos marca en estos momentos un incierto camino de preguntas por perseguir, no sólo acerca de los lugares en los que ya hemos estado, sino sobre todo de aquellos que aún nos esperan. Agradecemos a Isegoría la posibilidad de ofrecer este modesto mapa al lector contemporáneo. 